\title{
Glacial/interglacial variations in methanesulfonate (MSA) in the Siple Dome ice core, West Antarctica
}

\author{
Eric S. Saltzman, ${ }^{1}$ Irina Dioumaeva, ${ }^{1}$ and Brandon D. Finley ${ }^{1}$ \\ Received 27 December 2005; revised 20 April 2006; accepted 24 April 2006; published 8 June 2006.
}

[1] Methanesulfonate (MSA) in the Siple Dome ice core is a record of the deposition of biogenic sulfur to the West Antarctic ice sheet covering the past 100 kyr. Siple Dome MSA levels were low during the last glacial maximum, and increased to higher Holocene levels with a several kyr lag relative to the deglacial warming. The positive correlation between MSA and temperature at Siple Dome is similar to that in Greenland ice cores (Renland, GISP2, and GRIP), and stands in contrast to the negative correlation observed at Vostok, East Antarctica. The Siple Dome MSA data suggest that the sign of the high latitude dust/sulfur/climate feedback is negative, at least for the Pacific sector of the high latitude Southern ocean. These results challenge the idea that fertilization by increased dust deposition led to widespread increased DMS emissions from this region of the glacial Southern Ocean. Citation: Saltzman, E. S., I. Dioumaeva, and B. D. Finley (2006), Glacial/interglacial variations in methanesulfonate (MSA) in the Siple Dome ice core, West Antarctica, Geophys. Res. Lett., 33, L11811, doi:10.1029/ 2005 GL025629.

\section{Introduction}

[2] Oceanic sulfur emissions of dimethylsulfide (DMS) are believed to play an important role in earth's climate system as the precursor for sulfate aerosols and cloud condensation nuclei [Shaw, 1983; Charlson et al., 1987; Clarke et al., 1998]. DMS is a metabolic byproduct of the production of dimethylsulfoniopropionate (DMSP), which is produced primarily by haptophyte species of phytoplankton [Keller et al., 1989]. Methanesulfonate (MSA) is one of the atmospheric oxidation products of DMS. MSA and the $\mathrm{MSA} / \mathrm{nss}$ sulfate ratio are useful as tracers for biogenic sulfur [Saltzman et al., 1983], but the quantitative interpretation of these tracers is complicated by variations in the product distribution of DMS oxidation in the atmosphere, the aerosol dynamics of these compounds, and the possible depositional and postdepositional mobility of MSA in polar ice [Pszenny, 1992; Berresheim et al., 1995; Wagnon et al., 1999; Delmas et al., 2003].

[3] The Vostok ice core (and other East Antarctic ice cores) exhibits marked glacial interglacial variations in MSA and MSA/nss sulfate ratios, with maxima in both during glacials, and minima during interglacials [Legrand et al., 1991; Saigne and Legrand, 1987]. These signals are highly correlated with the climate signal as recorded in the $\delta^{18} \mathrm{O}$ and $\delta \mathrm{D}$ of water. The Vostok MSA signal has been

\footnotetext{
${ }^{1}$ Department of Earth System Science, University of California, Irvine, California, USA.
}

Copyright 2006 by the American Geophysical Union. 0094-8276/06/2005GL025629\$05.00 interpreted as indicating a greater atmospheric burden of DMS-derived aerosols during the glacial period. The importance of iron as a limiting nutrient in Southern Ocean waters has been demonstrated with in situ fertilization experiments [Boyd et al., 2000]. Given the high dust loading in Antarctic glacial ice, one can imagine that increased input of desert dust to the glacial Southern ocean stimulated phytoplankton growth, resulting in increased DMS emissions, marine sulfate aerosol and cloudiness. The climate forcing from this scenario (relative to the present day) would be cooling, due to both direct and indirect aerosol radiative effects. In this scenario, the sulfur/dust system would exert a positive feedback on climate, that is, stabilizing the glacial climate [Legrand et al., 1988; Watson and Liss, 1998].

[4] Measurements on Greenland ice cores show a different picture. The Renland, GISP2, and GRIP ice cores show an increase in MSA concentrations during deglaciation, suggesting that sulfur emissions from the North Atlantic and/or North Pacific were suppressed during glacial times [Hansson and Saltzman, 1993; Saltzman et al., 1997; Legrand et al., 1997]. The northern hemisphere high latitude oceans also experienced high glacial dust deposition [Yang et al., 1997], but it did not appear to cause increased DMS emissions. This apparent interhemispheric asymmetry in the behavior of ice core MSA remains a challenge to our understanding of the climatic role of the sulfur cycle.

[5] This project involved the measurement of MSA on the Siple Dome ice core. Siple Dome is located in West Antarctica $\left(81^{\circ} 65^{\prime} \mathrm{S}, 148^{\circ} 81^{\prime} \mathrm{W}, 621 \mathrm{masl}\right), 400 \mathrm{~km}$ from the edge of the Ross ice shelf. Siple Dome is strongly influenced by the incursion of marine air masses from the nearby Pacific sector of the Southern ocean. For this reason, Siple Dome should be a sensitive location for recording high latitude Southern Ocean emissions.

\section{Siple Dome Ice Core}

[6] The Siple Dome deep ice core was drilled as part of the NSF-sponsored WAISCORES drilling program. The Siple Dome site has an annual mean temperature of $-24.5^{\circ} \mathrm{C}$ and a modern average annual accumulation rate of $12.4 \mathrm{~cm}$ weq $/ \mathrm{yr}$. Dating of the Siple Dome ice core was based on a combination of layer counting and correlation of methane variations to the GISP2 ice core [Taylor et al., 2005; Brook et al., 2005].

[7] Longitudinal, rectangular subsamples of the core, approximately $3 \times 3 \times 20 \mathrm{~cm}$ in size, were analyzed. The samples were processed for ion chemistry by investigators at the University of Maine, using a continuous melter that samples the central portion of the subsample with minimal contamination from the exterior. Because of the thinning of annual 
layers downcore, the time period represented by a $20 \mathrm{~cm}$ long subsample ranged from approximately 2 years near the top of the core, to as much as 100 years at the base of the core. A total of nearly 5,000 samples were analyzed for MSA. The full data set is available at www.nsidc.org.

\section{Analytical Methods}

[8] MSA analyses were done by electrospray ionization with triple quadrupole mass spectrometry (ESI/MS/MS; ThermoFinnigan Quantum). Prior to analysis, $1 \mathrm{cc}$ aliquots of the samples were diluted 50:50 with methanol. The methanol was spiked with an internal standard of deuterated MSA $\left(\mathrm{CD}_{3} \mathrm{SO}_{3}^{-}\right)$. Samples were injected from a $20 \mu \mathrm{l}$ sample loop into a $200 \mu \mathrm{l} / \mathrm{min}$ methanol carrier stream, which was pumped continuously into the electrospray source.

[9] MSA was detected in negative ion SRM mode, using the 95/80 mass transition, corresponding to the $\mathrm{CH}_{3} \mathrm{SO}_{3}^{-}$ parent ion and the $\mathrm{SO}_{3}^{-}$ion fragment). The deuterated internal standard was monitored at the 98/80 transition, corresponding to the $\mathrm{CD}_{3} \mathrm{SO}_{3}^{-}$parent ion and $\mathrm{SO}_{3}^{-}$ion fragment. The concentration of MSA in the sample was calculated from the relative response of the MSA and deuterated MSA signals. Calibration was done using aqueous standards diluted gravimetrically from $>98 \%$ pure methanesulfonic acid (Acros Organics). The data acquisition time for each sample was 1 minute, and the entire analysis cycle (autosampler injection, needle rinsing, etc.) was 3 minutes per sample. All samples were run in duplicate. The mean rsd of duplicate analysis was $1.5 \%$. The detection limit of the analysis is approximately $0.1 \mathrm{ppb}$. Samples for which duplicates varied by more than $5 \%$ were reanalyzed. A comparison of 59 Siple Dome ice core samples analyzed by both ion chromatography and electrospray mass spectrometry yielded a correlation coefficient of 0.97 .

[10] All previous measurements of MSA in polar ice have been made using ion chromatography. The primary advantage of the EI/MS/MS technique is speed. Conventional ion chromatographic analysis of MSA takes on the order of 30 60 minutes per sample. Precision of the electrospray technique is also better, owing to the internal isotope standard, and the ability to routinely run samples in duplicate or triplicate. The principal disadvantage of the technique for ice core analysis is that it cannot analyze the complete spectrum of major inorganic ions.

\section{Results and Discussion}

[11] MSA concentrations in the Siple Dome ice core ranged from 1.7-73.2 ppb, with an overall mean of 14.5 $\pm 6.3 \mathrm{ppb}$ (Figure 1). During the glacial period, MSA exhibited a mean concentration of about $10 \mathrm{ppb}$. The highest glacial MSA levels were about $50 \mathrm{kyr}$, and the minimum occurred around $35 \mathrm{kyr}$. During the initial stages of deglaciation, MSA levels remained fairly constant. Between 13 and $12 \mathrm{kyr}$, during the last phase of rapid warming, MSA abruptly increased to around $20 \mathrm{ppb}$, overshooting the mean Holocene level. This rapid increase occurred on a time scale of approximately 1000 years. Siple Dome Holocene MSA levels are characterized by an overall increasing trend, with a marked dip at around $6 \mathrm{kyr}$.

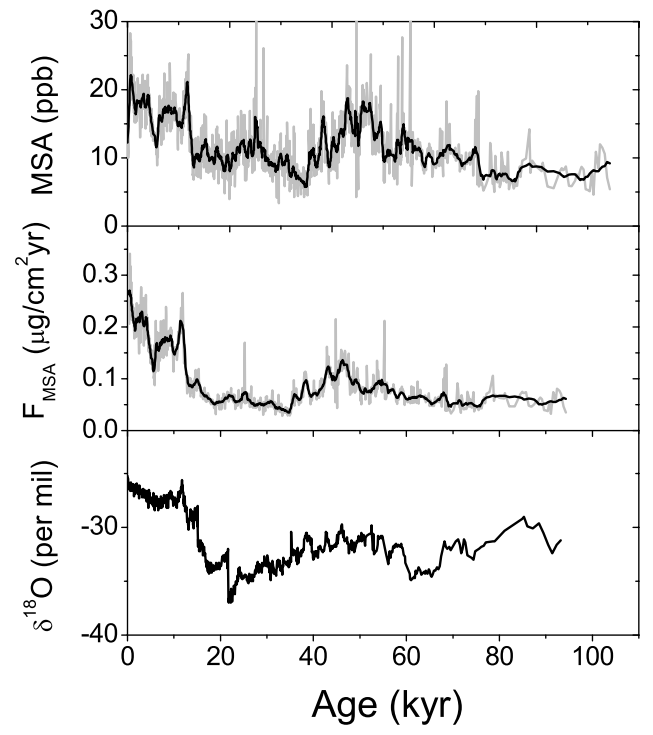

Figure 1. Siple Dome MSA concentration, depositional flux, and $\delta^{18} \mathrm{O}$ [Brook et al., 2005] in ice vs. ice age. Light gray, 50 year binned average; black, 500 year running average.

[12] The most striking aspect of the Siple Dome record is the fact that MSA increased during deglaciation, in contrast to the sharp decrease observed in the Vostok ice core. In this regard Siple Dome bears a greater resemblance to MSA in the Greenland ice sheet than to East Antarctica. The Siple Dome record clearly does not exhibit the very strong correlation between $\delta \mathrm{D}$ or $\delta^{18} \mathrm{O}$ and MSA observed in the Vostok ice core.

[13] One inference that may be drawn from this data, is that the change in MSA across the glacial/interglacial at Siple Dome is not controlled by postdepositional loss of MSA due to volatilization. If it were, one would expect glacial levels to be higher than Holocene levels, both because of reduced temperature and because of the increased alkalinity in glacial ice. The same argument applies to the Greenland ice cores [Saltzman et al., 1997].

[14] MSA and other aerosol-borne ions are incorporated in polar ice via both dry and wet depositional processes. The concentration of these ions in polar ice reflect both changes in atmospheric concentration, and dilution effects due to variations in accumulation. To the extent that dry deposition is important, increasing accumulation rates during deglaciation could dampen the observed changes in the ice core MSA signal relative to the changes in paleoatmospheric MSA levels. This effect is illustrated by the depositional flux of MSA, $F_{M S A}$, calculated as the product of MSA concentration in ice and the ice accumulation rate (estimated by Brook et al. [2005]). The influence of accumulation exaggerates the glacial/interglacial difference in $F_{M S A}$ relative to MSA concentration. Although the "efficiency" of deposition may change from glacial to interglacial, it is likely that the changes in atmospheric loading at Siple Dome lie somewhere between $F_{M S A}$ and MSA concentration. The relationship between $F_{M S A}$ and MSA concentration is similar here to that in the GISP2 MSA record [Saltzman et al., 1997]. 
[15] Another complication in the interpretation of ice core MSA records is that the yield of MSA produced in the atmosphere from the oxidation of DMS by $\mathrm{OH}$ is temperature-dependent. The yield of MSA from DMS oxidation is inversely related to temperature [Arsene et al., 1999], and there is abundant evidence for temperaturedependent branching in the DMS oxidation pathways [Hynes et al., 1986; Williams et al., 2001]. Such branching is likely the cause of latitudinal variations in the MSA/nss sulfate ratio observed in modern aerosols. This effect alone should lead to a decrease in MSA during deglaciation as the atmosphere warmed. This is another "damping" factor, suggesting that the increase MSA at Siple Dome is a strong signal indicating a significant change in the regional sulfur cycle.

[16] One of the most notable features in this record is the apparent lag in the MSA increase relative to the warming associated with deglaciation. The MSA response to warming did not occur until about $13 \mathrm{kyr}$, while warming clearly started several thousand years earlier. The glacial/interglacial MSA transition occurred abruptly and simultaneously with the resumption of warming after the Antarctic cold reversal [Brook et al., 2005]. This transition follows the major retreat of the West Antarctic ice sheet, which has been dated between 15 and $12 \mathrm{kyr}$ [Anderson et al., 2002]. This feature is not obvious in other Siple Dome ion records (P. Mayewski, unpublished data, 2003), and hence is unlikely to reflect a widespread reorganization of atmospheric transport patterns. It is possible that the glacial/interglacial MSA increase reflects a rapid transition from multi-year to seasonal sea ice in the Ross Sea. Correlation between seasonal sea ice extent and coastal Antarctic MSA levels has been documented at certain sites for decadal time scales [Welch et al., 1993; Curran et al., 2003], but the relationship on longer time scales has not yet been established.

[17] The 6 kyr dip in the Siple Dome MSA record is the major feature in the Holocene. A decrease at this time is surprising, as it coincides with the timing of the major retreat of the grounded Ross ice shelf [Licht, 2002; Anderson et al., 2002]. At the same time, in the Taylor Dome ice core in the Trans Antarctic mountains, MSA levels increased sharply and remained elevated for the remainder of the Holocene [Steig et al., 1998]. Apparently, the western Ross Sea was not a significant source of MSA for Siple Dome region at this time.

[18] There is clearly similarity between the Siple Dome and GISP2 ice core records in terms of their phasing relative to the glacial cycle. However, there are also significant differences in the behavior of MSA between the two cores during deglaciation. At GISP2 MSA decreased slightly at the onset of warming, spiked sharply at the Younger Dryas, then slowly increased, reaching Holocene levels several thousand years after warming was complete. The long time constant associated with the MSA transition in Greenland is suggestive of a forcing related to ocean circulation or ice sheet melting while the apparently rapid transition in Siple Dome suggests a forcing with less inertia, such as sea ice extent.

[19] Why is the Siple Dome MSA record so different from that of Vostok? Deuterium excess and general circulation models indicate that sites in the interior of East Antarctica have undergone significant climate-mediated changes in the location of their moisture sources. During the early Holocene, Vostok experienced increasing input of moisture from the lower latitudes of the Indian Ocean [Vimeux et al., 2001; Cosme et al., 2005]. This suggests that the strong anticorrelation of temperature and MSA concentration in the Vostok ice core may reflect a shift in source region from high to low latitude during deglaciation.

[20] By contrast, Siple Dome is currently primarily influenced by high latitude Pacific sector Southern ocean sources. Variations in major ion chemistry at Siple Dome over the past two hundred years, have been attributed to changes in the location and strength of low pressure systems over the Amundsen and Ross Seas [Kreutz et al., 1997]. Today, these regions exhibit extensive blooms of Phaeosystis antarctica, a colonial, bloom-forming algae, associated with copious production of DMSP [Ditullio and Smith, 1996].

\section{Implications for the Dust/Sulfur/Climate Hypothesis}

[21] The Siple Dome MSA record does not provide evidence of high DMS from the high latitude glacial Southern ocean. This contradicts arguments based on the Vostok ice core, that a glacial/interglacial change in the dust-induced fertilization of the glacial Southern ocean exerted a major change in climate forcing through direct or indirect (cloud-related) aerosol effects. How is this possible, given that iron fertilization studies demonstrate the high sensitivity of Southern ocean productivity to iron fertilization, and glacial dust levels were clearly higher than current levels?

[22] DMS production varies widely among different groups of phytoplankton, and DMS levels in surface seawater are a function of both production and loss due to microbial and photochemical processes. As a result, the relationship between primary productivity and sea surface DMS concentration is not necessarily a simple one. Iron fertilization studies have shown mixed results in terms of DMS production, exhibiting increased DMS levels in some cases and not in others [Turner et al., 2004]. Fertilization experiments are typically carried out on time scales of days or weeks. It is not known to what extent the fertilized patches simulate the biological community structures associated with long-term increases in dust input and changes in other environmental parameters such as temperature, wind speed, mixed layer depths, cloudiness, etc. It has also been suggested that iron-induced changes in silica uptake in low latitude and subpolar HNLC regions caused export of silica to the glacial Southern Ocean, favoring diatom growth over coccolithophorids [Brzezinski et al., 2002; Matsumoto et al., 2002].

[23] The productivity of the glacial Southern Ocean is of great interest because of the potential for the biological pump in this region to control atmospheric $\mathrm{PCO}_{2}$, and therefore, climate. Because of the taxonomic specificity of DMSP production, the MSA record does not directly address the broader question of variations in primary productivity or carbon export. Geochemical records in circum-Antarctic sediment cores support the idea of increased glacial carbon export from the surface to the deep ocean, northward of the Antarctic polar front [Anderson et al., 2002]. There is evidence from sedimentary alkanones that this increased export may have been carried by cocco- 
lithophorids, as opposed to diatoms which dominate productivity in this region today. Coccolithophorids, like Phaeocystis, are members of the haptophyte class. These phytoplankton are DMSP producers, while diatoms are generally not. South of the Antarctic polar front, glacial sediments do not exhibit clear evidence of increased carbon export [Anderson et al., 2002]. It has been suggested that an ecosystem dominated by the mucilaginous Phaeocystis antarctica could have transported carbon to the deep ocean without leaving a sedimentary record. The Siple Dome MSA record clearly does not support a major, widespread increase in either Coccolithophorides or Phaeocystis antarctica in the glacial Pacific Southern ocean relative to that during the Holocene.

\section{Conclusions}

[24] The Siple Dome MSA record does not support the idea that DMS emissions from the Pacific sector of the glacial Southern Ocean were higher than during the Holocene. The direction and magnitude of the changes in Siple Dome MSA during deglaciation are broadly similar in to those observed in Greenland ice cores, suggesting that the high latitude dust/sulfur/climate feedback in both regions were negative in sign. This study highlights the need for additional deep ice cores around the periphery of Antarctica, to characterize the climatic sensitivity of sulfur emissions from the Indian and Atlantic sectors of the Southern Ocean.

[25] Acknowledgments. We thank the WAISCORES project office and field staff, the National Ice Core Lab, K. Taylor, P. Mayewski, E. Meyerson, A. Kurbatov, P.-Y. Whung, D. Wylie, J. White, J. Moore, J. Greaves, and B. Hart of Thermo Electron Corp. This research was supported by the NSF Office of Polar Programs.

\section{References}

Anderson, J. B., et al. (2002), The Antarctic Ice Sheet during the Last Glacial Maximum and its subsequent retreat history: A review, Quat. Sci. Rev., 21, 49-70.

Arsene, C., et al. (1999), FT-IR product study of the photo-oxidation of dimethyl sulfide: Temperature and $\mathrm{O}_{2}$ partial pressure dependence, Phys. Chem. Chem. Phys., 1, 5463-5470.

Berresheim, H., et al. (1995), Sulfur in the atmosphere, in Chemical Composition and Climate of the Atmosphere, edited by H. B. Singh, pp. $251-$ 307, Van Nostrand Reinhold, Hoboken, N. J.

Boyd, P. W., et al. (2000), A mesoscale phytoplankton bloom in the polar Southern Ocean stimulated by iron fertilization, Nature, 407, $695-702$.

Brzezinski, M. A., C. J. Pride, V. M. Franck, D. M. Sigman, J. L. Sarmiento, K. Matsumoto, N. Gruber, G. H. Rau, and K. H. Coale (2002), A switch from $\mathrm{Si}(\mathrm{OH})_{4}$ to $\mathrm{NO}_{3}^{-}$depletion in the glacial Southern Ocean, Geophys. Res. Lett., 29(12), 1564, doi:10.1029/2001GL014349.

Brook, E. J., et al. (2005), Timing of millennial-scale climate change at Siple Dome, West Antarctica, during the last glacial period, Quat. Sci. Rev., 24, 1333-1343.

Charlson, R. J., et al. (1987), Oceanic phytoplankton, atmospheric sulphur, cloud albedo and climate, Nature, 326, 655-661.

Clarke, A. D., et al. (1998), Particle nucleation in the tropical boundary layer and its coupling to marine sulfur sources, Science, 282, 89-92.

Cosme, E., F. Hourdin, C. Genthon, and P. Martinerie (2005), Origin of dimethylsulfide, non-sea-salt sulfate, and methanesulfonic acid in eastern Antarctica, J. Geophys. Res., 110, D03302, doi:10.1029/2004JD004881.

Curran, M. A., et al. (2003), Ice core evidence for Antarctic sea ice decline since the 1950s, Science, 302, 1203-1206.
Delmas, R. J., et al. (2003), Evidence for the loss of snow-deposited MSA to the interstitial gaseous phase in central Antarctic firn, Tellus, Ser. B, 55, $71-79$.

Ditullio, G. R., and W. O. Smith Jr. (1996), Spatial patterns in phytoplankton biomass and pigment distributions in the Ross Sea, J. Geophys. Res., 101(C8), 18,467-18,478

Hansson, M. E., and E. S. Saltzman (1993), The first Greenland ice core record of methanesulfonate and sulfate over a full glacial cycle, Geophys. Res. Lett., 20(12), 1163-1166.

Hynes, A. J., et al. (1986), Kinetics and mechanism of $\mathrm{OH}$ reaction with organic sulfides, J. Phys. Chem., 90, 4148-4156.

Keller, M. D., et al. (1989), Dimethylsulfide production in marine phytoplankton, in Biogenic Sulfur in the Environment, ACS Symp. Ser, vol. 393, edited by E. S. Saltzman and W. J. Cooper, pp. 167-182, Am. Chem. Soc., Washington, D. C.

Kreutz, K., et al. (1997), Bipolar changes in atmospheric circulation during the Little Ice Age, Science, 277, 1294-1295.

Legrand, M. R., et al. (1988), Climate forcing implications from Vostok icecore sulphate data, Nature, 334, 418-420.

Legrand, M. R., et al. (1991), Ice-core record of oceanic emissions of dimethylsulphide during the last climate cycle, Nature, 350, 144-146.

Legrand, M., C. Hammer, M. De Angelis, J. Savarino, R. Delmas, H. Clausen, and S. J. Johnsen (1997), Sulfur-containing species (methanesulfonate and $\mathrm{SO}_{4}$ ) over the last climatic cycle in the Greenland Ice Core Project (central Greenland) ice core, J. Geophys. Res., 102, 26,66326,680 .

Licht, K. J. (2002), The C-14 record of Late Pleistocene ice advance and retreat in the central Ross Sea, Antarctica, Arct. Antarct. Alp. Res., 34(3), $324-333$.

Matsumoto, K., J. L. Sarmiento, and M. A. Brzezinski (2002), Silicic acid leakage from the Southern Ocean: A possible explanation for glacial atmospheric $p \mathrm{CO}_{2}$, Global Biogeochem. Cycles, 16(3), 1031, doi:10.1029/2001GB001442.

Pszenny, A. A. (1992), Particle size distributions of methanesulfonate in the tropical Pacific marine boundary layer, J. Atmos. Chem., 14, 273-284.

Saigne, C., and M. Legrand (1987), Methanesulfonic acid in Antarctic ice, Nature, 330, 240-242.

Saltzman, E. S., D. L. Savoie, R. G. Zika, and J. M. Prospero (1983), Methane sulfonic acid in the marine atmosphere, J. Geophys. Res., 88, $10,897-10,902$.

Saltzman, E. S., P.-Y. Whung, and P. A. Mayewski (1997), Methanesulfonate in the Greenland Ice Sheet Project 2 ice core, J. Geophys. Res., 102, $26,649-26,658$.

Shaw, G. E. (1983), Bio-controlled thermostasis involving the sulfur cycle, Clim. Change, 5, 297-303.

Steig, E. J., et al. (1998), Changes in climate, ocean and ice-sheet conditions in the Ross embayment, Antarctica, at 6ka, Ann. Glaciol., 27, 305310

Taylor, K. C., et al. (2005), Dating the Siple Dome Antarctica, ice core by manual and computer interpretation of annual layering, J. Glaciol., 50, $453-561$.

Turner, S. M., M. J. Harvey, C. S. Law, P. D. Nightingale, and P. S. Liss (2004), Iron-induced changes in oceanic sulfur biogeochemistry, Geophys. Res. Lett., 31, L14307, doi:10.1029/2004GL020296.

Vimeux, F., et al. (2001), Holocene hydrological cycle changes in the Southern Hemisphere documented in East Antarctic deuterium excess records, Clim. Dyn., 17, 503-513.

Wagnon, P., et al. (1999), Loss of volatile acid species from upper firn layers at Vostok, Antarctica, J. Geophys. Res., 104, 3423-3431.

Watson, A. J., and P. S. Liss (1998), Marine biological controls on climate via the carbon and sulphur geochemical cycles, Philis. Trans. R. Soc. London, Ser. B, 353, 41-51.

Welch, K. A., et al. (1993), Methanesulfonic-acid in coastal Antarctic snow related to sea-ice extent, Geophys. Res. Lett., 20, 443-446.

Williams, M. B., et al. (2001), Kinetic and mechanistic studies of the $\mathrm{OH}-$ initiated oxidation of dimethylsulfide at low temperature: A reevaluation of the rate coefficient and branching ratio, Chem. Phys. Lett., 344, 61-67.

Yang, Q., P. A. Mayewski, M. S. Twickler, and S. Whitlow (1997), Major features of glaciochemistry over the last 110,000 years in the Greenland Ice Sheet Project 2 ice core, J. Geophys. Res., 102, 23,289-23,300.

I. Dioumaeva, B. D. Finley, and E. S. Saltzman, Department of Earth System Science, University of California, 3325 Croul Hall, Irvine, CA 92697-3100, USA. (eric.saltzman@uci.edu) 